REVIEW SERIES

\title{
Sleep · 3: Clinical presentation and diagnosis of the obstructive sleep apnoea hypopnoea syndrome
}

\author{
D Schlosshan, M W Elliott
}

Thorax 2004;59:347-352. doi: 10.1136/thx.2003.007179

Patients with OSAHS may present to a sleep clinic or to other specialists with symptoms that are not immediately attributable to the condition. The diagnostic methods available are reviewed.

\section{PRESENTATION TO SLEEP CLINICS}

Patients are predominantly referred to a sleep clinic because they complain of excessive daytime sleepiness (EDS) or their partner complains about the noise of their snoring or expresses concern about witnessed apnoeas. ${ }^{9}$

\section{Snoring}

Snoring is very common in the general population; $35-45 \%$ of men and $15-28 \%$ of women report habitual snoring. ${ }^{210}$ Loud intrusive snoring affects bed partners, family, and even neighbours. Noise pollution and its resulting social disability, relationship disharmony and threatened marriage break up ${ }^{11}$ is an important reason why the patient, often pressurised by their partner, seeks medical help. In this case the "patient" is often more correctly the partner as the individual concerned is not aware of any adverse affects from his/her snoring other than the irritation reported by others. Snoring is also the most frequent symptom of OSAHS, occurring in $70-95 \%$ of patients, ${ }^{12}$ but because it is so common in the general population it is a poor predictor of OSAHS. ${ }^{13}$ However, the absence of snoring makes OSAHS unlikely; only $6 \%$ of patients with OSAHS do not report snoring, ${ }^{14}$ but it should be appreciated that a patient's perception of his/her snoring may be inaccurate. Three quarters of patients who deny snoring turn out to snore when this is measured objectively. ${ }^{15}$ Whenever possible, an account from a third party should be obtained.

\section{Excessive daytime sleepiness}

Excessive daytime sleepiness is caused by fragmented sleep related to frequent arousals. Like snoring, it is common and a poor discriminator of the patient with OSAHS. $30-50 \%$ of the general population without OSAHS report moderate to severe sleepiness. ${ }^{10}{ }^{16}$ It is important to differentiate true sleepiness (the urge to sleep) from various forms of tiredness such as lethargy, malaise or exhaustion. Patients themselves may underreport their sleepiness, ${ }^{17}$ either because they are not aware of it or because there are social pressures to deny that it is a problem. They may not have considered other obvious causes of EDS such as drugs and shift work, and these

See end of article for authors' affiliations

Correspondence to:

Correspondence to:
DrM W Elliott, Department of Respiratory Medicine, St James's University Hospital, Beckett Street, Leeds LS'9 7TF, UK; mark.elliott@lineone.net general lack of awareness. Many of the symptoms are non-specific and have other possible causes. ${ }^{5}$ Failure to recognise OSAHS is costly both to the individual and to society; underdiagnosis is thought to cost the USA \$3.4 in additional medical costs per year. ${ }^{6}$ To figure must be added the cost of losses in productivity, accidents, etc. ${ }^{78}$

Because OSAHS is so common, has considerable effects upon patients and their partners, increases the risk of other diseases, can be effectively treated, and is so often unrecognised, it is important to improve the way these patients are diagnosed. The first step is to increase awareness among doctors and the general public and for a simple sleep history to become part of the normal systems review taught at medical school.

This review will focus both on how patients present to sleep clinics and how they may present to other specialists with symptoms that are not immediately attributed to OSAHS.
Abbreviations: AHI, apnoea/hypopnoea index; EDS, excessive daytime sleepiness; ESS, Epworth sleepiness scale; MSLT, multiple sleep latency test; MWT, maintenance of wakefulness test; ODI, oxygen desaturation index; OSAHS, obstructive sleep apnoea hypopnoea syndrome; PSG, polysomnography; RIP, respiratory inductance plethysmography; SDB, sleep disordered breathing 
should always be asked about in the history. The possibility of dual causes such as shift work and OSAHS should also be considered.

Several tools are available for measuring sleepiness both subjectively and objectively. There is no gold standard, but the easiest and most practical is the Epworth sleepiness scale (ESS). ${ }^{18}$ Drawbacks include poor correlation with the severity of OSAHS and the disadvantages that accompany any selfevaluated test such as misperception of sleep episodes and the possibility of cheating. The input of the partner is very useful. ${ }^{19}$ The major advantages of the ESS are that it is simple, quick, inexpensive, and has a high test-retest reliability. ${ }^{20}$ Objective tests have obvious advantages but are time consuming and may not reflect everyday activity. They include the multiple sleep latency test (MSLT), ${ }^{21}$ the maintenance of wakefulness test (MWT),22 and the Osler test. ${ }^{23}$ Patients may also have neurocognitive deficits and psychological problems such as difficulty concentrating, poor memory, cognitive performance and personality changes with irritability and mood swings. ${ }^{9}$ These problems may be of greater consequence to the patient than EDS, but routine psychometric assessment is not practical in clinical practice.

\section{Witnessed apnoeas and nocturnal choking}

Concern by the bed partner about breathing pauses witnessed during sleep is the third common reason for referral to a sleep clinic. However, bed partners rarely give a reliable account about apnoeas during sleep and even trained medical staff are poor at diagnosing respiratory events in patients with OSAHS through clinical observation. ${ }^{24}$ Female patients with OSAHS are less likely to report nocturnal apnoeas ${ }^{25} 26$ and witnessed apnoeas may be reported in up to $6 \%$ of the normal non-apnoeic population. ${ }^{25}$ The patient may report waking up with acute panic and choking. These episodes usually only last for a few seconds but can cause considerable distress, both to the patient and the partner. They have to be differentiated from other causes of nocturnal breathlessness such as paroxysmal nocturnal dyspnoea in the patient with left ventricular failure, nocturnal asthma, acute laryngeal stridor, or Cheyne-Stokes respiration in patients with heart failure. Episodes of breathlessness in these conditions usually last longer and/or there is other evidence of the condition in question.

\section{PRESENTATION TO OTHER SPECIALTIES}

The pathophysiological consequences of OSAHS can affect almost every organ in the body and patients can present to other medical specialties with symptoms related to, caused by, or exacerbated by OSAHS. ${ }^{27}$ It is important that clinicians are aware of the various ways in which OSAHS may manifest in their specialty, as in some cases treatment of the OSAHS results in an improvement in-or even complete resolution of-these symptoms. ${ }^{28-30}$ Furthermore, treatment of some conditions such as hypothyroidism ${ }^{31}$ and acromegaly ${ }^{32}$ may result in resolution of OSAHS. It is beyond the scope of this review to describe in detail the presentation to various medical specialties but an overview is given in table $1 . .^{33}{ }^{34}$

\section{DIAGNOSIS}

The diagnosis of OSAHS is based on the characteristic clinical features together with objective demonstration of sleep disordered breathing (SDB). The American Sleep Disorders Association (ASDA) has proposed guidelines and a classification of severity of OSAHS (box 1). ${ }^{20}$ This emphasises that the diagnosis of OSAHS is not based solely on the detection of respiratory events, but equally includes clinical factors such as sleepiness and impairment of social or occupational functioning.
Table 1 How OSAHS might present to non-sleep specialists

\begin{tabular}{|c|c|}
\hline & Presentation \\
\hline Cardiologist $^{89}$ & $\begin{array}{l}\text { Hypertension } \\
\text { Left ventricular hypertrophy } \\
\text { Nocturnal angina } \\
\text { Myocardial infarction } \\
\text { Arrhythmias, particularly } \\
\text { bradyarrhythmias } \\
\text { Heart failure } \\
\text { Cor pulmonale } \\
\text { Increased pulmonary artery pressure }\end{array}$ \\
\hline Psychiatrist ${ }^{90}$ & $\begin{array}{l}\text { Depression } \\
\text { Anxiety } \\
\text { Behavioural problems } \\
\text { Acute delirium }\end{array}$ \\
\hline Neurologist ${ }^{91-93}$ & $\begin{array}{l}\text { Refractory epilepsy } \\
\text { Stroke } \\
\text { Impaired rehabilitation post stroke } \\
\text { Headache on waking }\end{array}$ \\
\hline Anaesthetist $^{9495}$ & $\begin{array}{l}\text { Difficult intubation } \\
\text { Sensitivity to opioid analgesia and } \\
\text { sedation } \\
\text { Witnessed apnoeas during recovery }\end{array}$ \\
\hline Urologist ${ }^{1596}$ & $\begin{array}{l}\text { Nocturia } \\
\text { Impotence } \\
\text { Erectile dysfunction }\end{array}$ \\
\hline Endocrinologist $^{97}$ & $\begin{array}{l}\text { Hypothyroidism } \\
\text { Acromegaly } \\
\text { Diabetes }\end{array}$ \\
\hline ENT surgeon ${ }^{98}$ & $\begin{array}{l}\text { Snoring } \\
\text { Sore throat } \\
\text { Hoarse voice }\end{array}$ \\
\hline $\begin{array}{l}\text { Gastroenterologist }^{28} \\
\text { Haematologist }^{9} \\
\text { Respiratory physician }\end{array}$ & $\begin{array}{l}\text { Oesophageal reflux } \\
\text { Polycythaemia } \\
\text { Nocturnal shortness of breath } \\
\text { Respiratory failure }\end{array}$ \\
\hline
\end{tabular}

Box 1 American Sleep Disorders Association (ASDA) classification of OSAHS

- Sleepiness

- Mild: unwanted sleepiness or involuntary sleep episodes occur during activities that require little attention

- Moderate: unwanted sleepiness or involuntary sleep episodes occur during activities that require some attention

- Severe: unwanted sleepiness or involuntary sleep episodes occur during activities that require active attention

- Sleep related obstructive breathing events (apnoea, hypopnoea, and respiratory effort related arousals):

- Mild: 5-15 events/hour of sleep

- Moderate: 15-30 events/hour of sleep

- Severe: $>30$ events/hour of sleep

\section{Clinical assessment}

Clinical assessment alone is not sufficient to make the diagnosis of OSAHS. Even sleep experts have been reported to be wrong in $50 \%$ of cases when making the diagnosis on history and examination alone. ${ }^{143}$ None of the common presenting symptoms alone has sufficient discriminatory value to make an accurate diagnosis..$^{13}$ Combining constellations of symptoms can improve diagnostic accuracy. Loud 
snoring and witnessed apnoeas identified OSAHS with a sensitivity of $78 \%$ and a specificity of $67 \%{ }^{36}$ In a large study of 5000 subjects, those reporting habitual loud snoring and frequent breathing pauses were 3-4 times more likely to have an apnoea/hypopnoea index (AHI) of $>15$ than those who did not have any of these symptoms. ${ }^{37}$ These findings are in keeping with results from previous studies. ${ }^{13} 14363839$ Although obesity is an important risk factor for OSAHS, $50 \%$ of patients are not clinically obese (body mass index $\left.>30 \mathrm{~kg}^{2}\right) .{ }^{40}$ Location of fat deposition, especially anterolateral to the upper airway, is more important. ${ }^{40}$ Neck circumference has consistently been shown to be a strong predictor of OSAHS, ${ }^{41}{ }^{35}$ values of $<37 \mathrm{~cm}$ and $>48 \mathrm{~cm}$ being associated with a low and high risk, respectively. Certain craniofacial abnormalities are associated with OSAHS. Tonsillar hypertrophy, retrognathia, micrognathia, and certain facial configurations have been detected by cephalometry, MRI, or CT scans to be present in some patients with OSAHS, ${ }^{42}$ but are of little predictive value. However, some are potentially amenable to surgical correction. Routine upper airway imaging is not currently recommended.

\section{Clinical prediction models}

Prediction models for both primary and secondary care that calculate the probability of a patient having OSAHS using self-reported symptoms combined with demographic and anthropometric data have been developed to try to improve the predictive value of clinical variables. With increasing recognition of OSAHS, the demand for diagnostic services is rising and such models may help to select patients for further evaluation. One author claimed that the number of polysomnographic investigations could be reduced by nearly $40 \%$ using one such model. ${ }^{43}$ They are low cost and can be performed in the clinic; however, when tested prospectively, they have a high sensitivity (76-96\%) but a low specificity $(13-54 \%) .{ }^{43}$ Furthermore, most have not been validated in populations such as the elderly, ethnic minorities, and in the primary care setting, in all of which the presentation of OSAHS may be very different from that seen in a sleep clinic. ${ }^{44}$ Further validation of the clinical usefulness and cost effectiveness of such an approach is required.

\section{Tests for sleep disordered breathing}

Full polysomnography (PSG) is traditionally regarded as the gold standard for the diagnosis of OSAHS. Typically, it requires admission to hospital with a trained technician present throughout the night. It is time consuming, expensive, and the large variety of techniques, equipment, and diagnostic criteria used by different sleep centres make evaluation and comparison of PSG data difficult. ${ }^{45}$ Redline et al showed that the respiratory disturbance index can vary 10fold depending on the definitions of the respiratory variables used for the diagnosis of OSAHS. This could lead to a situation where the same patient could be diagnosed and treated in one centre and be declared not to have OSAHS in another. ${ }^{46}$ Furthermore, PSG has not undergone the rigorous evaluation of accuracy, reliability, and validity expected for a "gold standard" diagnostic test. ${ }^{45}$ The AHI, the primary index extracted from PSG, is poorly correlated with EDS, increases in normal people with age, ${ }^{47}$ and has not been shown to predict short or long term morbidity or mortality. This leads some authors to question whether PSG can be regarded as a gold standard and reference tool when evaluating alternative diagnostic tests. ${ }^{48} 49$

There are two different aspects to full PSG-monitoring of various parameters reflecting respiration and monitoring cortical brain activity to assess the presence or absence of sleep and its stage. The constraints of space preclude a comprehensive review of all the various devices available for the investigation of SDB, but the most important issues will be addressed.

\section{Monitoring of respiration}

The diagnosis of SDB rests upon detecting changes in oronasal airflow and respiratory effort to define apnoeas and hypopnoeas. However, increased work of breathing usually, but not always, associated with loud snoring alone can lead to sleep disruption and daytime symptoms. This has been described as the upper airway resistance syndrome. ${ }^{50}$ Whether it is part of the OSAHS spectrum or presents a distinct syndrome is controversial. ${ }^{51}{ }^{52}$ Classically, it requires measurement of changes in oesophageal pressure..$^{20}$ The definition of apnoeas and hypopnoeas is arbitrary and other respiratory effort related events ${ }^{20}$ and episodes of inspiratory flow limitation may be important.

In patients with moderate to severe OSAHS the reproducibility of the respiratory parameters from night to night is good. ${ }^{53}$ For milder OSAHS a single negative study may not exclude OSAHS and a second study should be considered..$^{54}$ Sleep position, acclimatisation to a foreign sleep environment, concurrent respiratory tract infections, and variable alcohol and drug use are thought to be responsible for night to night variability in both respiratory and sleep parameters. Most airflow sensors detect apnoeas reliably, but the detection and quantification of decreased flow needed to diagnose hypopnoeas depends on the type of sensor used. Hypopnoeas make up the majority of obstructive respiratory events $^{46}$ and therefore measurement needs to be reliable. Oronasal airflow can be measured using thermistors which detect changes in temperature with respiration. Unfortunately, the response is not linear and therefore they cannot be used to determine hypopnoeas reliably. Furthermore, their accuracy varies greatly depending on the position of the sensors, the sleep position of the patient, the presence of nasal obstruction, and the make of the thermoelement used. ${ }^{56}$ For these reasons the ASDA Task Force does not recommend thermoelements for the detection of obstructive respiratory events. ${ }^{20}$ Despite this, they continue to be used for flow detection in many commercially available sleep diagnostic systems. Nasal pressure sensors connected to the nose via nasal prongs are more accurate than thermoelements in detecting hypopnoeas. ${ }^{57}$ However, nasal pressure is falsely increased in the presence of nasal obstruction and there is a non-linear relation between nasal pressure and nasal flow. Square root linearisation of nasal pressure greatly increases the accuracy for quantifying hypopnoeas and detecting flow limitation. ${ }^{58} 59$ Mouth breathing can affect the measurement but pure mouth breathing is uncommon. ${ }^{60}$

Respiratory effort can be assessed in a number of different ways. Chest and abdominal wall motion can be measured by strain gauges, pressure transducers, or by measuring the impedance of wires placed around the chest and abdomen. This allows the distinction between central events, characterised by a reduction in respiratory effort, and obstructive events in which efforts continue, usually with a phase shift between chest wall and abdominal wall motion; as the diaphragm descends the abdomen moves out but, because of upper airway obstruction, the thorax is subjected to large negative pressures and is sucked in. Respiratory inductance plethysmography (RIP) detects changes in the volume of the chest and abdomen during inspiration and expiration and, when properly calibrated, the sum of the two signals can provide an estimate of tidal volume. ${ }^{61}$ However, calibration may be difficult to maintain throughout the night. ${ }^{62}$ RIP allows an acceptable semi-quantitative measurement of ventilation and therefore hypopnoeas. The ASDA Task Force recommends the use of RIP or measurement of nasal 
pressure using nasal cannulae to detect airflow and ventilation. ${ }^{20}$

\section{Monitoring of sleep}

Sleep quality and stage is monitored by electroencephalography (EEG), electro-oculography (EOG), chin electromyography (EMG) and analysed by criteria agreed in the 1960s. ${ }^{63}$ These have been modified subsequently, in particular with the recognition that much shorter periods of arousal (so called "micro arousals") may be important. Electrophysiological monitoring allows confirmation that sleep has taken place, gives data about the amounts of different sleep stages and sleep quality, and can quantify the number of arousals which might reasonably be expected to be a good predictor of one of the most important symptoms of obstructive sleep apnoea-namely, EDS. Unfortunately, a number of studies have failed to show any relationship between the arousal index or any other of the sleep quality variables with daytime symptoms. ${ }^{49}{ }^{64}{ }^{65}$ Furthermore, there is poor reproducibility of the scoring of arousals. ${ }^{66}$ Douglas et al $l^{67}$ showed that the addition of electrophysiological analysis of sleep did not alter the diagnosis in 200 consecutive patients being investigated for possible OSAHS. It could be diagnosed as accurately by measuring the number of apnoeas + hypopnoeas per time in bed as by the number of apnoeas + hypopnoeas per time asleep (AHI).

Despite its widespread use and many advocates, the evidence does not support the need for full PSG in the routine diagnosis of OSAHS. One other approach to the recording of sleep is wrist activity monitoring. Although it is not recommended routinely in the diagnosis, it may be a useful adjunct to a detailed history in the assessment of sleep disorders. ${ }^{68}$

\section{Objective confirmation of OSAHS}

Various different approaches have been developed. These range through attended full PSG, unattended full PSG, limited PSG to oximetry, or movement detectors alone. Split night studies have been used; in patients with an AHI of $>40$ recorded in the first 2 hours of PSG the diagnosis of OSAHS can be made reliably without proceeding to a full night study. The second part of the night can be used for continuous positive airway pressure (CPAP) titration with accurate CPAP estimation..$^{45}$ There is a trend for studies to be performed in the patient's home rather than hospital. Home studies have the theoretical advantage that patients can sleep in their own environment without occupying a hospital sleep laboratory bed, providing more representative data in a cost effective way. ${ }^{69}$ Failure due to technical problems can occur in 5-20\% of cases. ${ }^{45}{ }^{70}$ Repeat testing increases costs. Factors such as patient disability or transportation problems make home studies impractical for some. ${ }^{71}$ Further validation and evaluation of the cost effectiveness of home studies is required.

Limited sleep studies usually quantify obstructive respiratory events without recording sleep. They typically include the measurement of oronasal airflow, chest wall and abdominal effort, ECG and oxygen saturation $\left(\mathrm{SpO}_{2}\right)$. In addition, leg and eye movement, body position, and snoring may be recorded. The systems are usually portable and can be used at home. The potential advantages of these systems are that they are cheaper, less labour and time intensive, and technically less challenging. The main disadvantage is that the lack of sleep recording leads to uncertainty when deciding if respiratory events occur during wakefulness or sleep. Surrogates of sleep such as motion detectors ${ }^{72}$ and static beds $\mathrm{s}^{73}$ attempt to estimate times of wakefulness but are poorly validated and do not appear to improve sensitivity or specificity. ${ }^{45}$ Furthermore, the study by Douglas et $a l^{45}$ suggests that documentation of sleep does not affect the final diagnosis. Generally, there is good correlation between the AHI obtained from limited channel devices and PSG. ${ }^{74}$ The sensitivities and specificities of limited in-laboratory devices are $82-94 \%$ and $82-100 \%$, respectively. ${ }^{75}$ A systematic review in 1997 concluded that full PSG may not be necessary to diagnose OSAHS and that limited in-laboratory cardiorespiratory studies in patients with a clinical suspicion of OSAHS may suffice. ${ }^{77}$

\section{Newer techniques}

The effects of the large intrapleural pressure swings during obstructive respiratory events on the autonomic nervous system, pulse, and blood pressure have given rise to the development of newer non-invasive techniques to measure apnoea or hypopnoea.

Indirect measurement of peripheral vasoconstriction and transient tachycardia through a finger plethysmograph, ${ }^{78}$ analysis of very low frequency components of heart rate variability, ${ }^{79}$ and the measurement of the change of pulse transit time ${ }^{80}$ during apnoeas have revealed promising results. Furthermore, pulse transit time can be used to differentiate between obstructive and central events. ${ }^{81}$

\section{Pulse oximetry}

Transcutaneous nocturnal pulse oximetry is increasingly being used for initial screening for OSAHS as it is inexpensive and can be simply applied and interpreted. ${ }^{47}$ Oxygen desaturations are common with obstructive apnoeas but can be absent with hypopnoeas or in events with increased upper airway resistance. They also occur frequently in other cardiovascular and respiratory conditions unrelated to airway obstruction, resulting in false positive results. The parameters reported vary widely but include total number of desaturations, oxygen desaturation index (ODI), desaturations per hour, highest, lowest and mean $\mathrm{SpO}_{2}$, and cumulative time $\mathrm{SpO}_{2}$ spent below $90 \%$. A $4 \%$ desaturation is most commonly considered to be significant, but 3\% and 5\% desaturations are also used. As with the AHI criteria, there is no consensus as to the ODI which represents a normal or abnormal result but commonly used thresholds are ODI $>5,>10$, and $>15$. Nocturnal artefacts, inaccurate readings in obese patients, and the presence of hypotension and haemoglobin abnormalities can limit the accuracy of the results. Devices with low sampling rates, used in some home pulse oximeters to preserve memory, can significantly underestimate oxygen dips. ${ }^{82}$ Furthermore, it is important for there to be a visual print out of the oximeter trace; artefacts are more easily seen and the pattern of oximetry may indicate that the calculated AHI may be an underestimate-for instance, if the patient did not sleep for a period of the night.

The sensitivity of nocturnal pulse oximetry in the diagnosis of OSAHS ranges from $31 \%$ to $98 \%$ and specificity from $41 \%$ to $100 \%$. This wide range of reported sensitivities and specificities results from the great diversity in criteria definition, populations studied, and devices used..$^{83}$ In the study by Douglas et al $66 \%$ of patients with OSAHS could be diagnosed with oximetry alone, but many of the patients undiagnosed by oximetry had moderately severe OSAHS and benefited from treatment. ${ }^{67}$ Nocturnal pulse oximetry performed prospectively in 275 patients suspected of OSAHS in the laboratory and compared with full PSG reported sensitivities of $80 \%, 71 \%$ and $63 \%$ and specificities of $89 \%$, $93 \%$ and $99 \%$ for ODIs of $>5,>10$, and $>15$, respectively. ${ }^{84}$ The authors argued that the number of full PSG recordings could be reduced by up to $50 \%$ using nocturnal pulse oximetry.

Pulse oximetry is probably most useful in patients with a high suspicion for OSAHS based on clinical features..$^{83} 856$ The combination of a high ODI and high pretest clinical suspicion can be regarded as sufficient to make a diagnosis of 
OSAHS. Patients with suspected OSAHS who have a negative pulse oximetry trace or have significant concurrent respiratory or cardiovascular disease need further investigation. ${ }^{47}$ It may also be useful in excluding sleep apnoea in snorers with a low clinical suspicion for OSAHS. ${ }^{87}$ The $4 \%$ dip rate has been shown to be the best oximetry derived variable predicting symptomatic benefit from CPAP. ${ }^{88}$

\section{CONCLUSION}

The history and examination are key to making the diagnosis of OSAHS and are sometimes overlooked in the debate about which technology is most appropriate. The history should be targeted towards making the diagnosis, but also assessing disease severity, the impact on social and occupational function, as well as on the patient's quality of life. The presence of significant cardiovascular, respiratory, and neurological co-morbidity should also be determined. This assessment should include the bed partner's report whenever possible. In a significant proportion of patients the diagnosis can be made by oximetry alone, and in most of the remainder by limited PSG although close attention needs to be given to the parameters recorded and the instruments used. Full PSG remains useful in research and for occasional patients who cannot be diagnosed using the simpler strategies. The future lies in the development of less intrusive systems to identify accurately those patients most likely to benefit from treatment.

\section{Authors' affiliations}

D Schlosshan, M W Elliott, Department of Respiratory Medicine, St James's University Hospital, Leeds LS9 7TF, UK

\section{REFERENCES}

1 Phillipson EA. Sleep apnea-a major public health problem. N Engl J Med 1993;328:1271-3

2 Ohayon MM, Guilleminault C, Priest RG, et al. Snoring and breathing pauses during sleep: telephone interview survey of a United Kingdom population sample. BMJ 1997;314:860-3.

3 Young T, Evans L, Finn L, et al. Estimation of the clinically diagnosed proportion of sleep apnea syndrome in middle-aged men and women. Sleep 1997;20:705-6.

4 Stores G, Crawford C. Medical student education in sleep and its disorders. J R Coll Physicians Lond 1998;32:149-53.

5 Strohl KP, Redline S. Recognition of obstructive sleep apnea. Am J Respir Crit Care Med 1996;154:279-89.

6 Kapur V, Blough DK, Sandblom RE, et al. The medical cost of undiagnosed sleep apnea. Sleep 1999;22:749-55.

7 Findley L, Unverzagt M, Guchu R, et al. Vigilance and automobile accidents in patients with sleep apnea or narcolepsy. Chest 1995; 108:619-24.

8 Rodenstein DO. Sleep apnoea syndrome: the health economics point of view. Monaldi Arch Chest Dis 2000;55:404-10.

9 Day R, Gerhardstein R, Lumley A, et al. The behavioral morbidity of obstructive sleep apnea. Prog Cardiovasc Dis 1999;41:341-54.

10 Young T, Palta M, Dempsey J, et al. The occurrence of sleep-disordered breathing among middle-aged adults. N Engl J Med 1993;328:1230-5.

11 Jones TM, Swift AC. Snoring: recent developments. Hosp Med 2000;61:330-5

12 Whyte KF, Allen MB, Jeffrey AA, et al. Clinical features of the sleep apnoea/ hypopnoea syndrome. Q J Med 1989;72:659-66.

13 Flemons WW, Whitelaw WA, Brant R, et al. Likelihood ratios for a sleep apnea clinical prediction rule. Am J Respir Crit Care Med 1994; 150:1279-85

14 Viner S, Szalai JP, Hoffstein V. Are history and physical examination a good screening test for sleep apnea? Ann Intern Med 1991;115:356-9.

15 Hoffstein V, Mateika S, Anderson D. Snoring: is it in the ear of the beholder? Sleep 1994;17:522-6

16 Duran J, Esnaola S, Rubio R, et al. Obstructive sleep apnea-hypopnea and related clinical features in a population-based sample of subjects aged 30 to 70 yr. Am J Respir Crit Care Med 2001;163:685-9.

17 Engleman HM, Hirst WS, Douglas NJ. Under reporting of sleepiness and driving impairment in patients with sleep apnoea/hypopnoea syndrome. J Sleep Res 1997;6:272-5.

18 Johns MW. A new method for measuring daytime sleepiness: the Epworth sleepiness scale. Sleep 1991;14:540-5.

19 Kingshott RN, Sime PJ, Engleman HM, et al. Self assessment of daytime sleepiness: patient versus partner. Thorax 1995;50:994-5

20 Sleep-related breathing disorders in adults: recommendations for syndrome definition and measurement techniques in clinical research. The report of an American Academy of Sleep Medicine Task Force. Sleep 1999;22:667-89.
21 Carskadon MA, Dement WC, Mitler MM, et al. Guidelines for the multiple sleep latency test (MSLT): a standard measure of sleepiness. Sleep 1986;9:519-24

22 Sangal RB, Thomas L, Mitler MM. Maintenance of wakefulness test and multiple sleep latency test. Chest 1992;101:898-902.

23 Bennett LS, Stradling JR, Davies RJ. A behavioural test to assess daytime sleepiness in obstructive sleep apnoea. J Sleep Res 1997;6:142-5.

24 Haponik EF, Smith PL, Meyers DA, et al. Evaluation of sleep-disordered breathing. Is polysomnography necessary? Am J Med 1984;77:671-7.

25 Young T, Hutton R, Finn L, et al. The gender bias in sleep apnea diagnosis. Are women missed because they have different symptoms? Arch Intern Med 1996; 156:2445-51

26 Redline S, Kump K, Tishler PV, et al. Gender differences in sleep disordered breathing in a community-based sample. Am J Respir Crit Care Med 1994;149:722-6.

27 Smith R, Ronald J, Delaive K, et al. What are obstructive sleep apnea patients being treated for prior to this diagnosis? Chest 2002;121:164-72.

28 Ing AJ, Ngu MC, Breslin AB. Obstructive sleep apnea and gastroesophageal reflux. Am J Med 2000; 108(Suppl 4a):120-5S.

29 Kerr $\mathbf{P}$, Shoenut JP, Millar T, et al. Nasal CPAP reduces gastroesophageal reflux in obstructive sleep apnea syndrome. Chest 1992;101:1539-44.

30 Pepperell JC, Ramdassingh-Dow S, Crosthwaite N, ef al. Ambulatory blood pressure after therapeutic and subtherapeutic nasal continuous positive airway pressure for obstructive sleep apnoea: a randomised parallel trial. Lancet 2002;359:204-10.

31 Rajagopal KR, Abbrecht PH, Derderian SS, et al. Obstructive sleep apnea in hypothyroidism. Ann Intern Med 1984;101:491-4.

32 Grunstein RR, Ho KK, Sullivan CE. Effect of octreotide, a somatostatin analog, on sleep apnea in patients with acromegaly. Ann Intern Med 1994;121:478-83.

33 Skomro RP, Kryger MH. Clinical presentations of obstructive sleep apnea syndrome. Prog Cardiovasc Dis 1999;41:331-40.

34 Strohl KP, Redline S. Recognition of obstructive sleep apnea. Am J Respir Crit Care Med 1996:154:279-89.

35 Hoffstein V, Szalai JP. Predictive value of clinical features in diagnosing obstructive sleep apnea. Sleep 1993;16:118-22

36 Kapuniai LE, Andrew DJ, Crowell DH, et al. Identifying sleep apnea from self-reports. Sleep 1988;11:430-6.

37 Young T, Shahar E, Nieto FJ, et al. Predictors of sleep-disordered breathing in community-dwelling adults: the Sleep Heart Health Study. Arch Intern Med 2002; 162:893-900

38 Flemons WW, Tsai W. Quality of life consequences of sleep-disordered breathing. J Allergy Clin Immunol 1997;99:S750-6.

39 Maislin G, Pack Al, Kribbs NB, et al. A survey screen for prediction of apnea. Sleep 1995; 18:158-66.

40 Mortimore IL, Marshall I, Wraith PK, et al. Neck and total body fat deposition in nonobese and obese patients with sleep apnea compared with that in control subjects. Am J Respir Crit Care Med 1998;157:280-3.

41 Stradling JR, Crosby JH. Predictors and prevalence of obstructive sleep apnoea and snoring in 1001 middle aged men. Thorax 1991;46:85-90.

42 Schwab RJ. Upper airway imaging. Clin Chest Med 1998;19:33-54.

43 Rowley JA, Aboussouan LS, Badr MS. The use of clinical prediction formulas in the evaluation of obstructive sleep apnea. Sleep 2000;23:929-38.

44 Harding SM. Prediction formulae for sleep-disordered breathing. Curr Opin Pulm Med 2001;7:381-5.

45 Chesson AL Jr, Ferber RA, Fry JM, et al. The indications for polysomnography and related procedures. Sleep 1997;20:423-87.

46 Redline S, Kapur VK, Sanders MH, et al. Effects of varying approaches for identifying respiratory disturbances on sleep apnea assessment. Am J Respir Crit Care Med 2000;161:369-74.

47 Bennett JA, Kinnear WJ. Sleep on the cheap: the role of overnight oximetry in the diagnosis of sleep apnoea hypopnoea syndrome. Thorax 1999:54:958-9.

48 Redline S, Sanders M. A quagmire for clinicians: when technological advances exceed clinical knowledge. Thorax 1999;54:474-5.

49 Stradling JR, Davies RJ, Pitson DJ. New approaches to monitoring sleeprelated breathing disorders. Sleep 1996;19(9 Suppl):S77-84.

50 Guilleminault C, Stoohs R, Clerk A, et al. A cause of excessive daytime sleepiness. The upper airway resistance syndrome. Chest 1993;104:781-7.

51 Guilleminault C, Chowdhuri S. Upper airway resistance syndrome is a distinct syndrome. Am J Respir Crit Care Med 2000;161:1412-3.

52 Douglas NJ. Upper airway resistance syndrome is not a distinct syndrome. Am J Respir Crit Care Med 2000;161:1413-6.

53 Chediak AD, Acevedo-Crespo JC, Seiden DJ, et al. Nightly variability in the indices of sleep-disordered breathing in men being evaluated for impotence with consecutive night polysomnograms. Sleep 1996;19:589-92.

54 Littner M. Polysomnography in the diagnosis of the obstructive sleep apneahypopnea syndrome: where do we draw the line? Chest 2000;1 18:286-8.

55 Le Bon O, Hoffmann G, Tecco J, et al. Mild to moderate sleep respiratory events: one negative night may not be enough. Chest 2000;1 18:353-9.

56 Berg S, Haight JS, Yap V, et al. Comparison of direct and indirect measurements of respiratory airflow: implications for hypopneas. Sleep 1997; 20:60-4

57 Series F, Marc I. Nasal pressure recording in the diagnosis of sleep apnoea hypopnoea syndrome. Thorax 1999:54:506-10.

58 Montserrat JM, Farre R, Ballester E, et al. Evaluation of nasal prongs for estimating nasal flow. Am J Respir Crit Care Med 1997; 155:211-5.

59 Thurnheer R, Xie X, Bloch KE. Accuracy of nasal cannula pressure recordings for assessment of ventilation during sleep. Am J Respir Crit Care Med 2001;164:1914-9. 
60 Ballester E, Badia JR, Hernandez L, et al. Nasal prongs in the detection of sleep-related disordered breathing in the sleep apnoea/hypopnoea syndrome. Eur Respir J 1998;11:880-3.

61 Cantineau JP, Escourrou P, Sartene R, et al. Accuracy of respiratory inductive plethysmography during wakefulness and sleep in patients with obstructive sleep apnea. Chest 1992;102:1145-51.

62 Whyte KF, Gugger M, Gould GA, et al. Accuracy of respiratory inductive plethysmograph in measuring tidal volume during sleep. J Appl Physiol 1991:71:1866-71

63 Rechtschaffen A, Kales A. A manual of standard terminology, techniques and scoring system for sleep stages of human subjects. NIH Publication No 204. Bethesda: National Institute of Neurological Disease and Blindness, 1968.

64 Bennett LS, Langford BA, Stradling JR, et al. Sleep fragmentation indices as predictors of daytime sleepiness and nCPAP response in obstructive sleep apnea. Am J Respir Crit Care Med 1998;158:778-86.

65 Stradling JR, Barbour C, Glennon J, et al. Prevalence of sleepiness and its relation to autonomic evidence of arousals and increased inspiratory effort in a community based population of men and women. J Sleep Res 2000;9:381-8.

66 Drinnan MJ, Murray A, Griffiths CJ, et al. Interobserver variability in recognizing arousal in respiratory sleep disorders. Am J Respir Crit Care Med 1998; 158:358-62.

67 Douglas NJ, Thomas S, Jan MA. Clinical value of polysomnography. Lancet 1992;339:347-50

68 Broughton R, Fleming J, Fleetham J. Home assessment of sleep disorders by portable monitoring. J Clin Neurophysiol 1996;13:272-84.

69 Whittle AT, Finch SP, Mortimore IL, et al. Use of home sleep studies for diagnosis of the sleep apnoea/hypopnoea syndrome. Thorax 1997;52:1068-73

70 Quan SF, Howard BV, Iber C, et al. The Sleep Heart Health Study: design, rationale, and methods. Sleep 1997;20:1077-85.

71 Portier F, Portmann A, Czernichow P, et al. Evaluation of home versus laboratory polysomnography in the diagnosis of sleep apnea syndrome. Am J Respir Crit Care Med 2000;162:814-8.

72 Middelkoop HA, Knuistingh NA, van Hilten JJ, et al. Wrist actigraphic assessment of sleep in 116 community based subjects suspected of obstructive sleep apnoea syndrome. Thorax 1995;50:284-9.

73 Svanborg E, Larsson H, Carlsson-Nordlander B, et al. A limited diagnostic investigation for obstructive sleep apnea syndrome. Oximetry and static charge sensitive bed. Chest 1990;98:1341-5.

74 Verse T, Pirsig W, Junge-Hulsing B, et al. Validation of the POLY-MESAM seven-channel ambulatory recording unit. Chest 2000;117:1613-8.

75 Lloberes $\mathrm{P}$, Montserrat JM, Ascaso A, et al. Comparison of partially attended night time respiratory recordings and full polysomnography in patients with suspected sleep apnoea/hypopnoea syndrome. Thorax 1996:51:1043-7.

76 Carrasco O, Montserrat JM, Lloberes P, et al. Visual and different automatic scoring profiles of respiratory variables in the diagnosis of sleep apnoeahypopnoea syndrome. Eur Respir J 1996;9:125-30.

77 Ross SD, Sheinhait IA, Harrison KJ, et al. Systematic review and metaanalysis of the literature regarding the diagnosis of sleep apnea. Sleep 2000;23:519-32.

78 Schnall RP, Shlitner A, Sheffy J, et al. Periodic, profound peripheral vasoconstriction-a new marker of obstructive sleep apnea. Sleep 1999:22:939-46.

79 Shiomi T, Guilleminault C, Sasanabe R, et al. Augmented very low frequency component of heart rate variability during obstructive sleep apnea. Sleep 1996; 19:370-7.
80 Smith RP, Argod J, Pepin J, et al. Pulse transit time: an appraisal of potential clinical applications. Thorax 1999;54:452-8

81 Argod J, Pepin JL, Levy P. Differentiating obstructive and central sleep respiratory events through pulse transit time. Am J Respir Crit Care Med 1998; 158:1778-83.

82 Wiltshire N, Kendrick AH, Catterall JR. Home oximetry studies for diagnosis of sleep apnea/hypopnea syndrome: limitation of memory storage capabilities. Chest 2001;120:384-9.

83 Netzer N, Eliasson $\mathrm{AH}$, Netzer $\mathrm{C}$, et al. Overnight pulse oximetry for sleepdisordered breathing in adults: a review. Chest 2001;120:625-33.

84 Chiner E, Signes-Costa J, Arriero JM, et al. Nocturnal oximetry for the diagnosis of the sleep apnoea hypopnoea syndrome: a method to reduce the number of polysomnographies? Thorax 1999;54:968-71.

85 Golpe R, Jimenez A, Carpizo R, et al. Utility of home oximetry as a screening test for patients with moderate to severe symptoms of obstructive sleep apnea. Sleep 1999;22:932-7.

86 Deegan PC, McNicholas WT. Predictive value of clinical features for the obstructive sleep apnoea syndrome. Eur Respir J 1996;9:117-24.

87 Rauscher H, Popp W, Zwick H. Model for investigating snorers with suspected sleep apnoea. Thorax 1993;48:275-9.

88 Choi S, Bennett LS, Mullins R, et al. Which derivative from overnight oximetry best predicts symptomatic response to nasal continuous positive airway pressure in patients with obstructive sleep apnoea? Respir Med 2000;94:895-9.

89 Leung RS, Bradley TD. Sleep apnea and cardiovascular disease. Am J Respir Crit Care Med 2001; 164:2147-65.

90 Naegele B, Thouvard V, Pepin JL, et al. Deficits of cognitive executive functions in patients with sleep apnea syndrome. Sleep 1995;18:43-52.

91 Mohsenin V. Sleep-related breathing disorders and risk of stroke. Stroke 2001;32:1271-8.

92 Dyken M, Somers V, Ymada T, et al. Investigating the relationship between stroke and obstructive sleep apnoea. Stroke 1996;27:401-7.

93 Loh NK, Dinner DS, Foldvary N, et al. Do patients with obstructive sleep apnea wake up with headaches? Arch Intern Med 1999;159:1765-8.

94 Loadsman JA, Hillman DR. Anaesthesia and sleep apnoea. Br J Anaesth 2001:86:254-66.

95 Mehta Y, Manikappa S, Juneja R, et al. Obstructive sleep apnea syndrome: anesthetic implications in the cardiac surgical patient. J Cardiothorac Vasc Anesth 2000;14:449-53

96 Yamada A, Kamoda M, Ikezoe K, et al. A case of central alveolar hypoventilation syndrome associated with cerebral infarction. No To Shinkei (Brain \& Nerve) 1993:45:273-6.

97 Rosenow F, McCarthy V, Caruso AC. Sleep apnoea in endocrine diseases. J Sleep Res 1998;7:3-11.

98 Rombaux P, Bertrand B, Boudewyns A, et al. Standard ENT clinical evaluation of the sleep-disordered breathing patient; a consensus report. Acta Otorhinolaryngol Belg 2002;56:127-37.

99 Carlson JT, Hedner J, Fagerberg B, et al. Secondary polycythaemia associated with nocturnal apnoea-a relationship not mediated by erythropoietin? J Intern Med 1992;231:381-7.

100 Liam CK. Cor pulmonale due to obstructive sleep apnoea. Med J Malaysia 1993;48:347-50

101 Schnader J, Reddy MN, Heffner JE, et al. Clinical conference on management dilemmas: obstructive sleep apnea and respiratory failure. Chest 1999;1 16:1786-93.

102 Sturani C, Galavotti V, Scarduelli C, et al. Acute respiratory failure, due to severe obstructive sleep apnoea syndrome, managed with nasal positive pressure ventilation. Monaldi Arch Chest Dis 1994;49:558-60. 